\title{
Spontaneous Tubercular Nephrocutanous Fistula
}

\author{
Irfan Nazir Mir*1, Mir Mujtaba Ahmad ${ }^{2}$ and Hilal A Wani ${ }^{1}$ \\ ${ }^{1}$ Department of General Surgery, GMC, Srinagar, India \\ ${ }^{2}$ Department of General Surgery, HIMSR, India
}

Submission: September 27, 2017; Published: October 16, 2017

*Corresponding author: Irfan Nazir Mir, Department of General Surgery, GMC, Srinagar, India, Tel: 9906460646; Email: irfanazir@gmail.com

\begin{abstract}
Introduction: Spontaneous nephrocutaneous fistula is a rare manifestation of renal disease that can occur due to various etiologies, such as renal calculus, chronic pyelonephritis, stricture of the ureteropelvic junction, and renal tuberculosis (TB). An auto nephrectomy with a nephrocutaneous fistula due to renal tuberculosis can be diagnosed quite late if it is not suspected.

Case Presentation: We report a case of a spontaneous nephrocutaneous fistula with tuberculosis. A 65 year-old Diabetic male with recurrent flank pain and intermittent purulent drainage from his right flank region for the previous 6 months was admitted to our outpatient clinic. The patient was successfully treated with retrograde DJ stenting and excision of the fistulous tract, followed by anti tuberculous treatment. The pathological examination of the surgical specimen revealed calcifications, and necrotizing granulomatous inflammation suggestive of TB.
\end{abstract}

Conclusion: Urogenital TB is difficult to diagnose due to the lack of specific symptoms and signs. In the case of a nonfunctioning kidney without an obvious cause and a chronic spontaneous nephrocutaneous fistula, the possibility of associated renal TB should be kept in mind, especially in immune compromised patients.

Keywords: Auto nephrectomy; Nephrocutaneous Fistula; Tuberculosis; Chronic infection

\section{Introduction}

Cutaneous fistulae to adjacent organs are not uncommon but spontaneous communication between kidney and skin is rare and few cases are described in literature. Spontaneous nephrocutaneous fistula is a rare manifestation of renal disease that can occur due to various etiologies. Renal calculus and chronic pyelonephritis are the most common causes [1]. Genitourinary tuberculosis (TB) is seen in $15 \%-20 \%$ of patients with pulmonary TB in developing countries. Spontaneous nephrocutaneous fistula can be secondary to strictures at the ureteropelvicjunction, or to necrosis and scar formation due to renal TB. Fibrosis, necrosis, and scar formation in the renal parenchyma creates a weak area, from which the leak begins [2]. Renal TB can cause various complications, including auto nephrectomy in $11.5 \%$ of affected patients [3]. Here in, we report a rare case of spontaneous nephrocutaneous fistula with tuberculosis.

\section{Case Report}

We report a case of 65 years old male, hypertensive since 3 years on medication and diabetic since $2 \frac{1}{2} 2$ years on insulin, presents to our surgical outpatient department with chief complaints as follows:

a) External wound in right flank with continuous watery discharge- six months

b) Generalized weakness. There is also H/o fever on and off, history of weight loss as per patients statement.

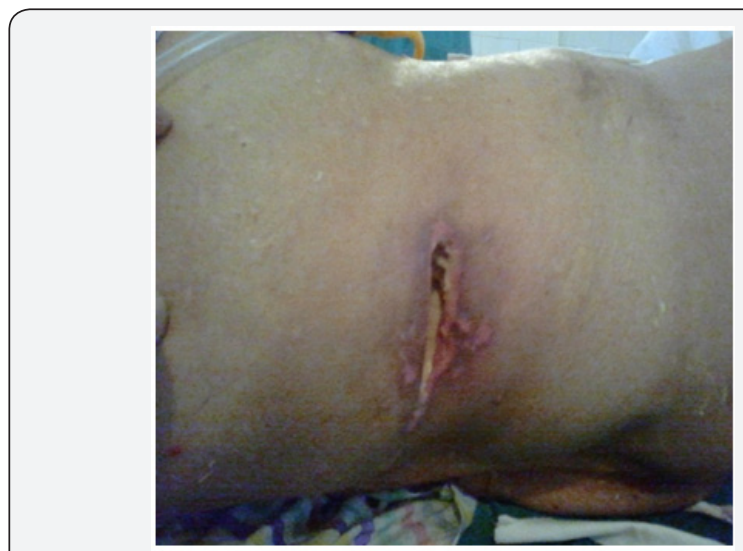

Figure 1: External Wound. 


\section{On examination}

Vitals were stable, pallor+, chest/ CVS: normal, P/A: soft, non-tender, dirty wound on right flank (Figures $1 \& 2$ ).

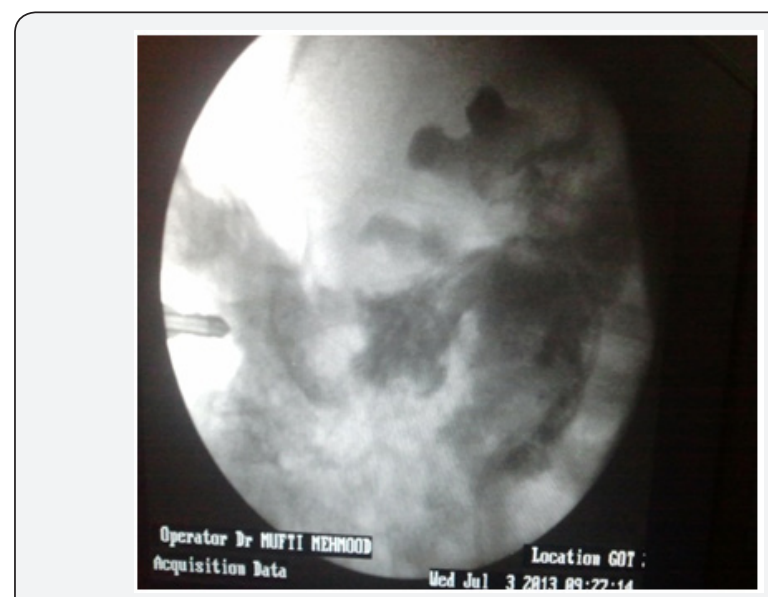

Figure 2: Dye Study Showing Extravasation.

\section{Management}

Patient was investigated and blood workup showed increased TLC count of 23000/cumm; urea level of $88 \mathrm{mg} / \mathrm{dl}$ and creatinine level of $1.43 \mathrm{mg} / \mathrm{dl}$.

a) Urine culture was done which showed no growth after 48 hours of incubation.

b) A KFT profile of draining fluid from wound was done which showed increased urea level $260 \mathrm{mg} / \mathrm{dl}$ and creatinine level of $6.8 \mathrm{mg} / \mathrm{gl}$.

c) A plain X-ray abdomen was normal and USG abdomen showed normal echo pattern of kidneys.

d) Patient was put on pyridium orally. Color changes in urine and extravasating fluid from wound were noted. The color of both urine and extravasating fluid changed to pink indicating that the fluid was nothing but urine from kidney communicating percutaneously.

e) Patient underwent cystoscopy with retrograde pyelography.

f) A DJ stent was placed cystoscopically in retrograde manner.

g) External wound was debrided with excision of the fistulous tract and laid open.

h) Patient was put on ATT after tubercular profile came positive.

\section{Diagnosis}

Spontaneous Tubercular Nephrocutaneous Fistula.

\section{Discussion}

Genitourinary TB is the second most common form of extrapulmonary TB, after peripheral lymphadenopathy.TB may involve the kidney as part of a generalized disseminated infection, or as localized genitourinary disease [4]. The development of disease depends on the cellular immune response of the host, which determines the outcome of the infection. The healing process results in fibrous tissue and the deposition of calcium salts can result in a nonfunctioning kidney, known as tuberculous autonephrectomy.Renal calcifications may occur commonly in $\mathrm{TB}$ and require surgical intervention. In the treatment of this complication, the aim is to ensure the protection of the renal tissue as much as possible [5]. Some authors have proposed nephrectomy in order to prevent reactivation, while others have recommended life-long follow up. With the development of antituberculous drugs, nephrectomy has become less important. According to the European Association of Urology Guidelines, the indications for nephrectomy include a non-functioning kidney with or without calcifications, extensive disease involving the whole kidney with hypertension and ureteropelvic junction obstruction, and coexisting renal carcinoma [5]. A spontaneous renal fistula to adjacent organs is not an uncommon condition; there are some cases of spontaneous nephrocutaneous fistula due to chronic renal TB.

The majority of fistulas presents spontaneous drainage through the lumbar region following those points with lowest resistance, such as the lumbar triangle (Petit) and the lumbar quadrilateral (Grynfeld), establishing a fistulous pathway that communicates the perirenal tissues and collecting system with the external environment [6,7]. Urogenital TB is difficult to diagnose due to the lack of specific symptoms and signs. Irritative lower urinary tract symptoms, hematuria, and pyuria are the most common complaints. Abnormal radiological findings, including pyelocaliceal dilatation, ureteral stricture, hydroureter, parenchymal destruction, autonephrectomy, and calcifications, can be seen in $61.5 \%$ of patients. A definite diagnosis cannot be made with these findings, but urogenital TB should be considered in the differential diagnosis. In the present case, the patient had leakage from the lumbar region for more than six months. Although he had received various antibiotics and medical treatments over a long period, no benefit was seen. This interesting case report of a delayed diagnosis shows us that in cases of a nonfunctioning kidney with a spontaneous nephrocutaneous fistula, we must keep in mind the possibility of associated renal TB, especially inimmuno compromised patients or in geographic areas where TB is a common health problem.

\section{Conflict of Interest}

This case report was done in the division of urology for academic purposes and was not funded by any external fund, the submission has no commercial interests, and the authors of this case report are not linked to any external agencies.

\section{References}

1. Sarmiento RC, Blasco CF, Herrera FF, Chica Rusillo A, Ostale Gomez J (1990) Spontaneous nephrocutaneous fistula. Report of a case and review of the literature. Arch Esp Urol 43(3): 411-413. 
2. Maheshwari PN, Shah HN (2005) Nephrocutaneous fistula through percutaneous nephrolithotomy scar: rare presentation of genitourinary tuberculosis. Urology 66(3): 655-656.

3. Yazdani M, Shahidi S, Shirani M (2008) Urinary polymerase chain reaction for diagnosis of urogenital tuberculosis. Urol J 5(1): 46-49.

4. Lin YL, Fan YC, Cheng CY, Sue YM, Hsu YH, et al. (2008) The case: Sterile pyuria and an abnormal abdominal film. Kidney Int 73(1): 131-133.
5. Cek M, Lenk S, Naber KG, Bishop MC, Johansen TE, et al. (2005) EAU guidelines for the management of genitourinary tuberculosis. Eur Urol 48(3): 353-362.

6. Qureshi (2007) Spontaneous nephrocutaneous fistula in tuberculous pyelonephritis. J Coll Physicians Surg Pak 17(6): 367-368.

7. Ansari MS, Singh I, Dogra PN (2004) Spontaneous nephrocutaneous fistula-2 unusual case reports with review of literature. Int Urol Nephrol 36(2): 239-243.

\section{Your next submission with Juniper Publishers will reach you the below assets}

- Quality Editorial service

- Swift Peer Review

- Reprints availability

- E-prints Service

- Manuscript Podcast for convenient understanding

- Global attainment for your research

- Manuscript accessibility in different formats

(Pdf, E-pub, Full Text, Audio)

- Unceasing customer service

Track the below URL for one-step submission

https://juniperpublishers.com/online-submission.php 